\title{
Study on Waste Composition at Taman Pura Kencana, Batu Pahat
}

\author{
Aeslina Abdul Kadir ${ }^{1,}$, Noor Amira Sarani ${ }^{1}$, Siti Fatimah Onthong ${ }^{1}$, and Mohd Ikhmal \\ Haqeem Hassan ${ }^{1}$ \\ ${ }^{1}$ Department of Water and Environmental Engineering, Faculty of Civil and Environmental \\ Engineering, Universiti Tun Hussein Onn Malaysia, 86400, Parit Raja, Batu Pahat, Johor, Malaysia
}

\begin{abstract}
Municipal solid waste management is a major challenge due to the increase in population and the development of a country. The problems also arise when the lifespan of the landfills available are shorten than estimated. The aim of this study is to determine waste composition at Taman Pura Kencana. The waste collection was carried out for 50 houses on a daily basis. The collection and sorting out method was conducted based on Malaysian Standard MS 2505:2012 and the data collected is recorded. The result showed the moisture content was approximately ranging between $25 \%-30 \%$. The density for each waste has been calculated and the result was recorded accordingly. The highest density is metal followed by organic waste, glass, napkins, household hazardous waste, textiles, paper, plastic rigid, plastic film, rubber and tetrapek. The waste collected also were categorized and consisted of food waste/organic (43.75\%), paper (17.97\%), plastics rigid (13.58\%), plastic film $(10.62 \%)$, napkins $(4.43 \%)$, glass $(3.10 \%)$, household hazardous waste $(1.68 \%)$, metal $(1.67 \%)$, tetrapek $(1.34 \%)$, rubber $(0.93 \%)$, and textiles $(0.92 \%)$. Results from the analysis illustrated that waste generation in Taman Pura Kencana may influenced by sudden changes in lifestyles, incomes, household size and also increase of population.
\end{abstract}

\section{Introduction}

Municipal solid waste management (MSW) becomes a great challenge in development plans throughout the world, especially in rapidly growing cities. One of the most successful countries in transition is Malaysia. Steady economic growth and low unemployment rates driven by stable political conditions and plenty of resources that making Malaysia at same level as developed country [1].

Malaysia is experiencing rapid industrialization and urbanization giving the adverse effects on the environment from the increasing of waste generated. Similar to many other countries, rapid urbanization and industrialization also have changed the characteristics of Malaysian solid waste generated [2]. Furthermore, waste generation rates also increase due to the demand of Malaysian for better quality of life. Nevertheless, waste management is to reduce the amount of waste being produced, thus reducing the disposal costs, the impact on

* Corresponding author: aeslina@uthm.edu.my 
the environment, and the impact on human health [3]. The typical solid waste management system practiced in developing country brings many problems such as low collection coverage and irregular collection services, crude open dumping and burning without air and water pollution control and the breeding of vermin and flies. It was reported in 2003, the average amount of municipal solid waste generation per capita per day ranged is between 0.5 to $0.8 \mathrm{~kg}$ but recently the range has increased 0.5 to $2.5 \mathrm{~kg}$, especially in the major cities such as Kuala Lumpur and Petaling Jaya [4]. The national strategic plan on solid waste management estimated that the waste generation rate will increases by $3.59 \%$ per year based on population growth projections for the period of 2002 to 2020 . Based on that projection, the total waste management in peninsular Malaysia was 23000 tons/day in 2010 and 25000 tons/day in 2012. In 2020, the amount of waste to be generated has been estimated to reach 30000 tons/day [4].

Recently, one of the major concerns is municipal solid waste in residential area. Residential area is potentially exposed to pollution and threat with solid waste disposal. Each house at residential area has the ability to generate solid waste. This situation occurred due to lack of awareness about cleanliness, recycling and effect to the environment, community and existing landfill. Moreover, lacks of solid waste management at residential area also contribute to increase solid waste disposal. Different houses produce different compositions of solid waste based on occupants of house. It is important to identify and evaluate the composition of solid waste at the residential area to determine the most items disposed. Therefore, in this study, the composition of solid waste at Taman Pura Kencana was conducted to determine the most waste disposed from this residential area.

\section{Materials and methods}

In order to measure the composition of waste produced, the materials and methods were discussed in this section.

\subsection{Sampling area}

The study was conducted in private properties that covering housing area at Taman Pura Kencana which is limited to 50 units of single-storey houses for a month. However, the sampling size of the collected household reached minimum $200 \mathrm{~kg}$ of waste weight; therefore it is not necessary to fulfill the requirement for collecting household waste at those 50 units of houses.

\subsection{Questionnaire}

The survey was conducted to obtain data from each household. The survey is to identify basic information from household and also to get their permission to participate in the study. All the households were briefed regarding the procedure on the waste collection from their house.

\subsection{Sampling process}

This study is focusing on waste retained and waste discarded which include the waste kept at home for recycling or reuses purpose, as well as the unwanted waste placed at the collection point. Therefore, waste retained and waste discarded generally becomes the main contributor to the total amount of waste generation from a household. 
This study also focusing on the sampling of waste as-generated at household, the waste was collected by the student themselves. At the fieldwork, samples were collected by randomly choosing houses in a row within the area of study and these houses were taken for 'as-generated' samples. Then, the residents were provided with two plastics bags labeled organic and non-organic on daily basis to put all their waste into these bags accordingly. Before the collection, the residents were briefed on the procedure and were informed on not to throw any of organic or inorganic recyclable waste during the study out of the house. Time had been arranged between student and household to collect the waste on a daily basis. After the collection process, the organic, non-recyclable and recyclable items were weighed separately and recorded accordingly. Then, the samples were sent for sorting and the procedure was repeated until the required numbers of houses were complete.

\subsection{Waste classification and weight of waste composition}

The sample waste was sorted and classified into waste composition components as listed. Wide and sufficient area with the flat platform was important for sorting process. Then the wastes were divided accordingly to its composition based on specific description for each category of waste. The description is essential to help recognize the constituents of each waste category.

The total weight of waste composition was determined by weighing all the categories of household waste after the waste was spread on a clean plastic bags and segregation was done by hand. The weight of waste composition then was recorded on the worksheet and illustrated in term of percentage.

\subsection{Moisture content}

The moisture content of waste composition was determined. Normally, moisture content of solid wastes expressed in percentage or weight. In the wet weight method, the moisture in a sample is expressed as percentage of the wet weight materials meanwhile in dry weight method, it is expressed as percentage of the dry weight material.

Moisture content is the quantity of water contained in a material such as textiles, foods, and wood. Water content is applied in an extensive range of scientific and technical areas and is expressed as a ratio, which can range from zero to the value of the materials porosity at saturation. However, the waste sample in this study was dried in oven at $105^{\circ} \mathrm{C}$ in order to gain the value for dry weight.

\section{Results and discussion}

\subsection{Survey}

\subsubsection{Estimation of recyclable waste by weight}

Result from the survey in Fig. 1 shown that organic waste dominates the amount of wastes produced with $80 \mathrm{~kg}$ followed by recyclable wastes which are papers, magazine and plastic rigid with $11.5 \mathrm{~kg}, 11.0 \mathrm{~kg}$ and $9.95 \mathrm{~kg}$ accordingly. This trend might be due to daily cooking activities by the occupants. The amount for other wastes such as newspaper $(9.7 \mathrm{~kg})$, plastic $(8.1 \mathrm{~kg})$, others $(7.0 \mathrm{~kg})$, aluminum can $(6.7 \mathrm{~kg})$, glass bottle $(5.9 \mathrm{~kg})$ and plastic bag $(3.5 \mathrm{~kg})$ 
respectively. Nevertheless, the data might be not too accurate as some of respondents did not answer the questionnaire thoroughly for the first week.

\subsubsection{Estimation of recyclable waste by quantity}

During the survey process, data analysis in Fig. 2 shows food waste had the highest with 210 followed by paper (197), plastic rigid (175), plastic drinking (150) and napkins (90). The highest number of food waste produced may contribute by residents who are not working and stay at home as housewives. Lower number of waste produced was contribute by aluminium can (79), newspaper (65), and glass bottle (52) produced by residents at Taman Pura Kencana.

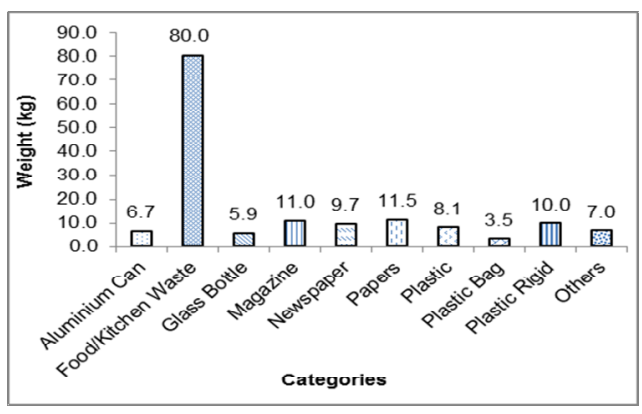

Fig. 1. Estimation of recyclable waste by weight from survey

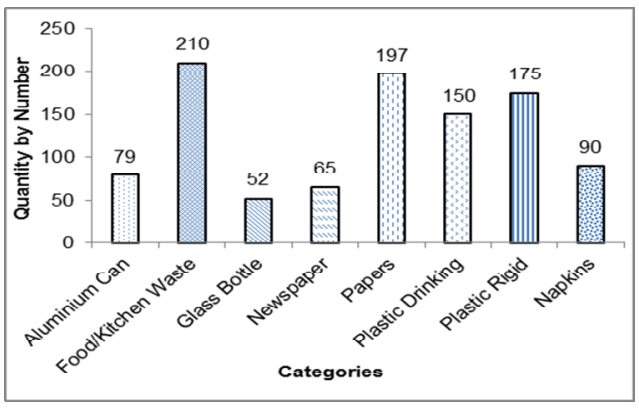

Fig. 2. Estimation of recyclable waste by quantity from survey

\subsection{Waste generation and composition}

\subsubsection{Estimation of organic and inorganic waste generation}

Solid waste generation rates offer an estimation of the amount of waste produced by residence over a certain period of time. Refer to Fig. 3 and Fig. 4, comparison between organic and inorganic waste generation for each day is shown. From day 1 to day 7, organic waste was produced almost the same amount of waste and do not have too much differences between each day. The same trend also occurred to inorganic waste where similar data was collected which is $20.26 \mathrm{~kg}, 19.43 \mathrm{~kg}, 20.48 \mathrm{~kg}, 14.6 \mathrm{~kg}, 16.66 \mathrm{~kg}, 19.49 \mathrm{~kg}$ and $15.04 \mathrm{~kg}$ respectively.

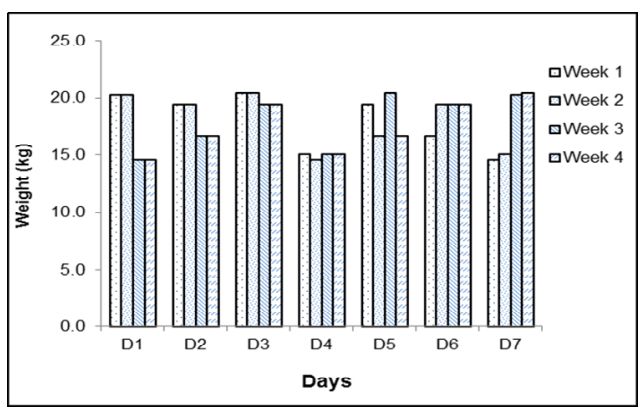

Fig. 3. Waste generation for organic waste

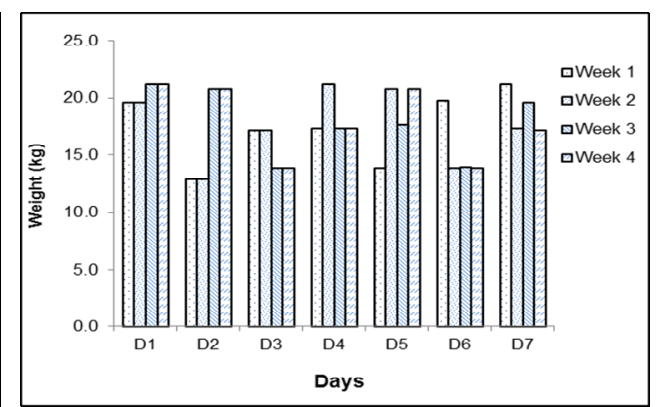

Fig. 4. Waste generation for inorganic waste 


\subsubsection{Composition of waste disposal for each week}

Fig. 5 illustrates the percentage of waste by its category. Based on Fig. 5, it can be concluded that the highest percentage of waste produced at Taman Pura Kencana was food waste which is $47.87 \%$. The second highest waste being produced was paper with $17.41 \%$. Next, plastic rigid, plastic film, metal, napkins and glass which is $11.12 \%, 9.19 \%, 5.58 \%$, $3.68 \%$ and $2.41 \%$ respectively. Tetrapek, textiles and rubber waste are all considered as lowest waste production and each contribute not more than $2 \%$.

Fig. 6 indicates the classification of waste at Taman Pura Kencana according to category by percentage. The pattern of waste production is still the same compared with the sample at first week. Similar to solid waste collected at week 1 , food waste is still the highest waste being produced in Taman Pura Kencana which is $46.96 \%$ in total for 7 days, followed by paper $(18.34 \%)$, plastic rigid $(14.85 \%)$ and plastic film $(9.46 \%)$. The other categories hold the lowest waste productions which are napkins by $3.92 \%$ and glass by $2.95 \%$ while other categories obtained less than $2 \%$ each.

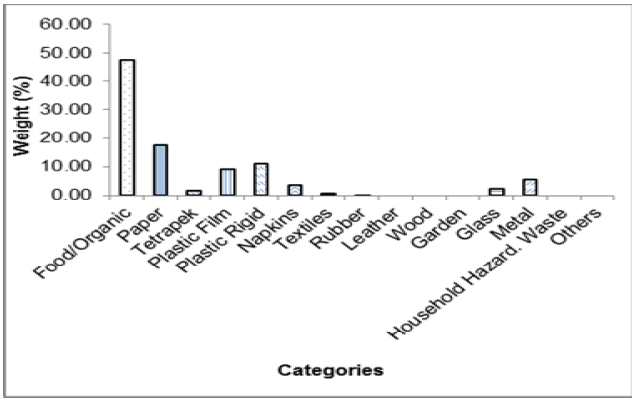

Fig. 5. Composition of waste disposal (Week 1)

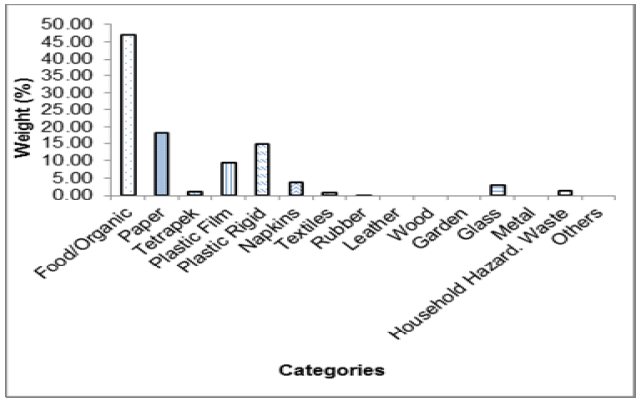

Fig. 6. Composition of waste disposal (Week 2)

Fig. 7 illustrates the percentage of waste by its category. It can be concluded that the highest of waste produce in Taman Pura Kencana was food waste which is $39.52 \%$. the second highest waste being produced was paper (17.91\%). Next, plastic rigid and plastic film which is $13.92 \%$ and $12.39 \%$ respectively. Rubber, tetrapek and textiles waste are all considered as lowest waste generation. Rubber and tetrapek each contribute to $2.02 \%$ and $1.49 \%$ respectively and textiles contribute less than $1 \%$ of the total waste produce in Taman Pura Kencana.

Fig. 8 illustrates the percentage of waste by its category. Based on Fig. 8, it can be concluded that the highest percentage of waste produced at Taman Pura Kencana was food waste which is $40.62 \%$. The second highest waste being produced was paper with $18.22 \%$. Next, plastic rigid, plastic film, napkins and glass which is $14.42 \%, 11.44 \%, 4.94 \%$, and $3.88 \%$ respectively. Tetrapek, textiles, metal, household hazardous waste, and rubber waste are all considered as lowest waste production and each contribute not more than $3 \%$.

\subsection{Moisture content}

The results show that values of the moisture content for waste collection in first week are $28.85 \%$, second week $27.40 \%$, third week $26.5 \%$ and $26.51 \%$ for the fourth week. Usually, the determination of moisture content of wastes may assist in obtaining water content of wastes and thus scientifically quantity the leachate generated in landfill. In addition, moisture contents also the important element during the treatment process of waste incineration and composition. 


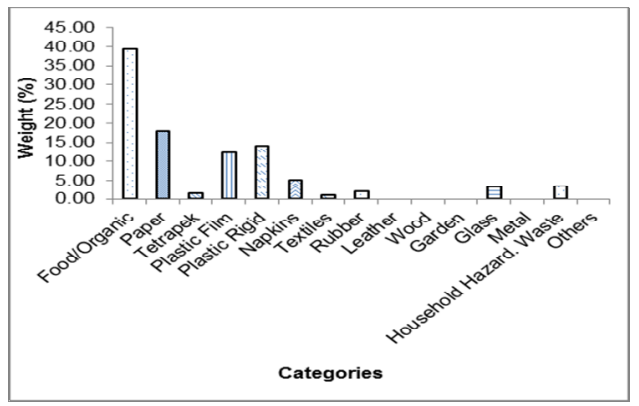

Fig. 7. Composition of waste disposal (Week 3)

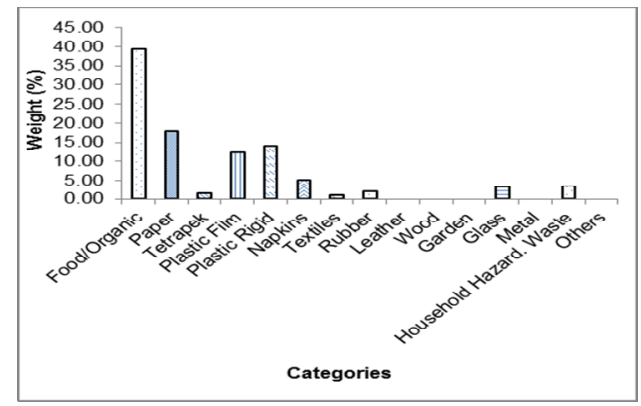

Fig. 8. Composition of waste disposal (Week 4)

\section{Conclusions}

The waste generation in Taman Pura Kencana may influenced by sudden changes in lifestyles, incomes, household size and also increase of population. These have been explained on the variability between the data of the waste composition. As in Taman Pura Kencana mainly consists of housewives and working person, so their buying power is high to live. In the meantime, information on types of waste is important for separation process, collection and recycling. It would help to understand the influence of socio-economic status and lifestyle on solid waste generation. The results conclude that amount of organic waste is still the highest followed by plastics and paper. The eating habits and family size of the residents of the study area, on the other hand, can influence the household weight significantly. It is suggested to improve proper disposing facilities for recyclable items at each houses, therefore the waste generated is fully under the responsibility of each household's resident. The future research is highly needed in order to gain more reliable information regarding household waste composition and generation rate.

The results presented in this paper are part of an ongoing postgraduate research. The authors would like to thank the Faculty of Civil and Environmental Engineering, UTHM for this study.

\section{References}

[1] M.N. Hassan, T.L. Chong, M.M. Rahman, M.N. Salleh, Z. Zakariah, M. Awang and M.N. Yunus, Solid waste management - What's the Malaysian position, Seminar on Waste to Energy, Universiti Putra Malaysia, (2000)

[2] G. Tchobanoglous, H. Theisen and S. Vigil, Integrated solid waste management engineering principles and management issues, McGraw-Hill, (1993)

[3] A.M.A. Latifah, M.A.A. Samah and M.Z.N. Iyana, Municipal solid waste in Malaysia: Practices and challenge, J. Waste Management, 29, 2902-2906, (2009)

[4] U.N. Ngoc and H. Schnitzer, Sustainable solutions for solid waste management in Southeast Asian countries, Waste Management, 29, 1982-1995, (2009) 